Jurnal THEOREMS (The Original Research of Mathematics) Vol. 5 No. 1, Juli. hal. 32-40

URL: http://jurnal.unma.ac.id/index.php/th

Naskah masuk: 2020-04-11 Naskah diperbaiki:2020-06-04 Naskah diterima:2020-07-13

\title{
PERBANDINGAN KEMAMPUAN BERPIKIR KREATIF \\ MATEMATIS MELALUI PEMBELAJARAN TREFFINGER DAN \\ CREATIVE PROBLEM SOLVING
}

\section{COMPARISON OF MATHEMATIC CREATIVE THINKING ABILITY THROUGH TREFFINGER LEARNING WITH CREATIVE PROBLEM SOLVING}

\author{
Iis Nursilawati ${ }^{1}$, Iik Nurhikmayati ${ }^{*}$, Erik Santoso ${ }^{3}$ \\ 123Pendidikan Matematika, FKIP, Universitas Majalengka, 45475, Indonesia \\ ${ }^{*}$ E-mail: ik.nurhikmayati@gmail.com \\ Hp: 085256103150
}

\begin{abstract}
ABSTRAK
Penelitian ini bertujuan untuk menganalisis perbandingan peningkatan kemampuan berpikir kreatif matematis siswa melalui pembelajaran treffinger dan pembelajaran creative problem solving. Metode yang digunakan adalah quasi eksperimen dengan the pretest post-test two treatment desain. Populasi penelitian ini adalah seluruh siswa kelas XI SMAN 1 Leuwimunding. Sampel dilakukan dengan teknik random sampling dengan jumlah 33 siswa kelas XI IPA 3 sebagai kelas eksperimen 1 dan 33 siswa kelas XI IPA 4 sebagai kelas eksperimen 2. Teknik analisis yang digunakan adalah analisis data kuantitatif pretes dan postes dengan uji Mann Whitney. Hasil penelitian menunjukan bahwa tidak terdapat perbedaan peningkatan kemampuan berpikir kreatif matematis siswa antara siswa yang mendapatkan pembelajaran treffinger dengan siswa yang mendapatkan pembelajaran Creative Problem Solving.
\end{abstract}

Kata kunci: kemampuan berpikir kreatif matematis, treffinger dan creative problem solving.

\section{ABSTRACT}

This study aims to analyze the comparison of increasing mathematical creative thinking skills through Treffinger learning with creative problem solving learning. The method used is a quasi experiment with the pretest post-test two treatment design. The study population was all students of class XI SMAN 1 Leuwimunding. Samples were carried out by random sampling technique with 33 students of Class XI Science 3 as experimental class 1 and 33 students of Class XI Science 4 as experimental class 2 . The analysis technique is the analysis of quantitative data pretest and posttest with the Mann Whitney test. The results showed that there was no difference in the increase in students' mathematical creative thinking abilities between students who received treffinger learning and students who learned Creative Problem Solving learning.

Keywords: mathematical creative thinking skills, treffinger learning and creative problem solving learning 


\section{PENDAHULUAN}

Pendidikan adalah salah satu faktor penting bagi sebuah bangsa. Semakin maju pendidikan, semakin maju pula negara tersebut. Majunya sebuah negara dapat dilihat dari Sumber Daya Manusia (SDM) yang berkualitas. Salah satu upaya pendidikan dalam menghasilkan SDM yang berkualitas adalah pendidikan matematika. Dalam proses pembelajaran matematika, siswa dapat memperoleh latihan secara implisit maupun secara eksplisit dengan cara berpikir kreatif, terutama dalam memecahkan suatu masalah.

Dikemukakan dalam Peraturan Pemerintah Nomor 17 Tahun 2010 dalam kurikulum 2013 tentang Pengelolaan dan Penyelenggaraan Pendidikan, yang menyebutkan bahwa tujuan penyelenggaraan pendidikan dasar dan menengah yaitu membangun landasan bagi berkembangnya potensi siswa agar menjadi manusia yang berilmu, cakap, kritis, kreatif, dan inovatif. Salah satu tujuan yang hendak dicapai dalam pendidikan matematika adalah memiliki kemampuan berpikir kreatif. Kemampuan berpikir kreatif dapat melatih siswa untuk mengembangkan pengetahuannya dengan cara belajar aktif dan kreatif sehingga siswa dapat memperoleh pengalaman baru.

Menurut Hasanah (2019: 829) menyatakan bahwa "kemampuan berpikir kreatif merupakan kemampuan untuk memberikan gagasan baru, baik berupa gagasan maupun karya nyata yang relatif berbeda dengan apa yang telah ada". Menurut Andiyana (2018: 240) bahwa "kemampuan berpikir kreatif matematis adalah kemampuan berpikir yang bertujuan untuk menciptakan atau menemukan ide baru yang berbeda, tidak umum, orisinil yang membawa hasil yang pasti dan tepat".
Berdasarkan dua pendapat diatas kemampuan berpikir kreatif matematis adalah kemampuan seseorang untuk menciptakan hal baru yang beda dari biasanya dan memerlukan tingkat kemampuan berpikir tinggi untuk memperoleh suatu hal baru.

Mengembangkan kemampuan berpikir kreatif matematis merupakan hal yang sangat penting. Menurut Sari (2016: 31) memberikan alasan mengapa berpikir kreatif matematis merupakan hal yang penting bagi siswa karena "berfikir kreatif matematis dapat membantu siswa menjadi lebih berhasil dalam hal menyelesaikan masalah". Berpikir kreatif matematis merupakan kemampuan untuk melihat berbagai kemungkinan penyelesaian terhadap suatu masalah. Berpikir kreatif matematis juga dapat menciptakan kemungkinan-kemungkinan untuk memecahkan masalah-masalah yang timbul dimasa depan.

Berdasarkan observasi yang dilakukan peneliti di SMAN 1 lewimunding tahun ajaran 2018/2019, diketahui bahwa kemampuan berpikir kreatif di SMAN 1 Lewimunding masih dikatakan rendah. Hal ini terlihat pada saat siswa diberikan contoh soal pemecahan masalah yang dikerjakan bersama guru, siswa masih dapat memahaminya. Namun, ketika siswa diberikan contoh soal latihan atau masalah dengan tingkat kesulitan yang lebih tinggi, siswa terlihat kebingungan dan kesulitan dalam memahami dan menyelesaikannya. Kegiatan ini menyebabkan siswa kurang aktif dalam mengikuti pembelajaran.

Untuk mewujudkan harapan supaya siswa memiliki kemampuan berpikir kreatif matematis, dibutuhkan model pembelajaran yang dapat meningkatkan kemampuan berpikir kreatif matematis. Model pembelajaran yang diduga dapat meningkatkan 
kemampuan berpikir kreatif matematis adalah model pembelajaran Treffinger dan model pembelajaran Creative Problem Solving (CPS).

Menurut Shoimin "model pembelajaran Treffinger adalah sebuah pembelajaran yang bertujuan untuk mengembangkan kreativitas siswa dengan menggunakan keterampilan afektif dan kognitif yang termuat dalam tiga tingkatan yaitu basic tools, practice with proses, dan working with real problem". Setiap tingkatan pembelajaran didalam model Treffinger yang memiliki pemecahan masalah diberikan secara terurut dan terintergrasi. Mulai dari pemecahan masalah yang sederhana hingga pemecahan masalah yang kompleks sebagai tantangan nyata dalam penerapan, membuat siswa lebih menguasai materi yang diajarakan.

Menurut Lestari (2018: 65) "model pembelajaran CPS adalah variasi dari pembelajaran penyelesaian masalah dengan teknik yang sistematis dalam mengorganisasikan gagasan kreatif untuk menyelesaikan suatu masalah". Dalam proses pembelajaran CPS siswa dituntut untuk selalu melakukan aktivitas selama dalam proses pembelajaran melalui tahapan klarisifikasi masalah, pengungkapan pendapat, evaluasi dan implementasi.

Creative Problem Solving dan treffinger merupakan dua model pembelajaran yang berbeda tetapi memiliki konsep yang sama dalam upaya meningkatkan kemampuan berpikir kritis dilihat dari setiap tahapan pembelajarannya. Sampai saat ini belum ada penelitian yang membandingkan kedua pembelajaran tersebut. Hasil penelitian yang serupa oleh Simanjuntak, dkk (2019) dengan judul "Penerapan Model Pembelajaran Creative Problem Solving (CPS) Tipe Treffinger untuk Meningkatkan Berpikir
Kreatif pada Pokok Bahasan Larutan Penyangga" hanya fokus pada penerapan model CPS tipe treffinger bukan perbandingan kedua model.

Berdasarkan uraian diatas, maka peneliti tertarik untuk melihat bagaimana peningkatan kemampuan berpikir kreatif antar CPS dan Treffinger khususnya pada bidang matematika.

\section{METODE PENELITIAN}

Desain yang digunakan dalam penelitian ini adalah quasi eksperimen dengan bentuk the pretest post-test two treatmen desain. Sampel dalam penelitian ini adalah kelas XI IPA 3 sebagai kelas eksperimen 1 dan kelas XI IPA 4 sebagai kelas eksperimen 2 . Penelitian ini melibatkan dua kelompok yaitu kelompok eksperimen 1 yang diberikan pembelajaran dengan menggunakan model pembelajaran Treffinger dan kelompok eksperimen 2 yang diberikan pembelajaran dengan menggunakan model pembelajaran CPS. Pada desain ini kelompok eksperimen 1 maupun kelompok eksperimen 2 tidak dipilih secara random. Artinya peneliti hanya menentukan dua kelas yang akan dijadikan kelas eksperimen 1 dan kelas eksperimen 2 tanpa dipilih secara acak.

Selengkapnya mengenai desain penelitian ini bisa dilihat pada gambar 1 berikut ini:

$$
\begin{array}{lll}
\text { Eksperimen 1 :O } & X_{1} & O \\
\text { Eksperimen 2: } O & X_{2} & O
\end{array}
$$

\section{Gambar 1}

Desain Penelitian

Penelitian ini dilaksanakan di SMAN 1 Leuwimunding yang beralamat di Jalan Raya Utara Leuwimunding Kecamatan Leuwimunding Kabupaten Majalengka. 
Penelitian ini dilaksanakn di kelas XI IPA SMAN 1 Leuwimunding pada semester 1 Tahun Ajaran 2019/2020.

Teknik yang digunakan dalam penelitian ini adalah Random Sampling. Dalam pengumpulan data ini peneliti melakukan tes sebanyak dua kali yaitu pretest dan posttest. Pretest digunakan untuk mengukur kemampuan awal siswa, dan di uji cobakan di awal sebelum dilakukan perlakuan (treatment) kepada kelas eksperimen 1 dan kelas eksperimen 2 sedangkan posttest digunakan untuk mengukur kemampuan siswa setelah diberi perlakuan (treatment) tujuanya adalah untuk mengetahui hasil akhir dari kelas eksperimen 1 dan kelas eksperimen 2.

\section{HASIL DAN PEMBAHASAN HASIL PENELITIAN}

Untuk mengetahui kemampuan awal kemampuan berpikir kreatif matematis siswa, data pretes, postes dan $N$-Gain dianalisis secara deskriptif. Berikut hasil perhitungannya.

Tabel 1

Hasil Analisis Deskriptif Statistik Skor Pretes dan Postest Kelas Eksperimen 1 dan Kelas Eksperimen 2

\begin{tabular}{|c|c|c|c|c|c|c|}
\hline & Kelompok & N & Mean & $\begin{array}{c}\text { Std. } \\
\text { Deviasi }\end{array}$ & Min & Max \\
\hline \multirow{2}{*}{ Pretes } & Eks 1 & 33 & 56,82 & 8,083 & 45 & 70 \\
\cline { 2 - 7 } & Eks 2 & 33 & 56,82 & 8,274 & 45 & 70 \\
\hline \multirow{2}{*}{ Postes } & Eks 1 & 33 & 81,67 & 7,873 & 70 & 95 \\
\cline { 2 - 7 } & Eks 2 & 33 & 81,97 & 8,095 & 70 & 95 \\
\hline \multirow{2}{*}{ N-Gain } & Eks 1 & 33 & 0,55 & 23,27 & 0,00 & 87,50 \\
\cline { 2 - 7 } & Eks 2 & 33 & 0,56 & 23,81 & 0,00 & 87,50 \\
\hline
\end{tabular}

Berdasarkan tabel 1 diperoleh ratarata untuk pretes kelas eksperimen 1 sebesar 56,82, postes kelas eksperimen 1 sebesar 81,67 , pretes kelas eksperimen 2 sebesar 56,82, postes kelas ekperimen 2 sebesar 81,97. Sedangkan nilai $N$-Gain kelas eksperimen 1 sebesar 0,55 yang berkategori sedang, nilai $N$-Gain kelas eksperimen 2 sebesar 0,56 yang berkategori sedang. Maka dapat disimpulkan bahwa antara pretes kelas ekperimen 1, pretes eksperimen 2, dan $\mathrm{N}$-Gain mempunyai nilai rata-rata yang sama sebelum dilakukannya perlakuan (treatmen).

Untuk mengetahui apakah terdapat perbedaan antara kemampuan berpikir kreatif matematis siswa yang menggunakan model pembelajaran Treffinger dengan model pembelajaran CPS maka akan dilakukan uji-t. Tetapi sebelum melakukan uji-t, terlebih dahulu dilakukan uji persyaratan analisis diantaranya adalah uji normalitas dan uji homogenitas yang disajikan pada tabel 2.

Tabel 2

Hasil Uji Normalitas

\begin{tabular}{|l|c|c|c|}
\hline \multirow{2}{*}{} & \multicolumn{3}{|c|}{ Kolmogorov-Smirnov } \\
\cline { 2 - 4 } & Statistic & Df & Sig \\
\hline Pretes Eks 1 & 0,134 & 33 & 0,137 \\
\hline Postes Eks 1 & 0,135 & 33 & 0,135 \\
\hline
\end{tabular}

Copyright $@ 2020$, Jurnal THEOREMS (The Original Research of Mathematics) p-ISSN: 2528-102X, e-ISSN: 2541-4321, URL:http://jurnal.unma.ac.id/index.php/th 
Jurnal THEOREMS (The Original Research of Mathematics) Vol. 5 No. 1, Juli. hal. 32-40

URL: http://jurnal.unma.ac.id/index.php/th

Naskah masuk: 2020-04-11 Naskah diperbaiki:2020-06-04 Naskah diterima:2020-07-13

\begin{tabular}{|l|l|l|l|}
\hline Pretes Eks 2 & 0,135 & 33 & 0,136 \\
\hline Postes Eks 2 & 0,139 & 33 & 0,108 \\
\hline N-Gain Eks 1 & 0,158 & 33 & 0,035 \\
\hline N-Gain Eks 2 & 0,149 & 33 & 0,061 \\
\hline
\end{tabular}

Berdasarkan hasil perhitungan tabel 2 nilai signifikansi uji kolmogorovsmirnov nilai pretest eksperimen 1 diperoleh 0,137, nilai postest eksperimen 1 diperoleh 0,135 , nilai pretest eksperimen 2 diperoleh 0,136, dan nilai postest eksperimen 2 diperoleh 0,108. Sedangkan untuk uji $N$-Gain kelas eksperimen 1 diperoleh 0,035 dan kelas eksperimen 2 diperoleh 0,061 . Berdasarkan kriteria nilai pengujian maka diterima untuk kelas eksperimen 1 dan kelas eksperimen 2, Sedangkan untuk nilai $\mathrm{N}$-Gain ditolak untuk kelas eksperimen 1 dan kelas eksperimen 2 .

Dari hasil pengujian kolmogorovsmirnovdapat disimpulkan bahwa data pretest dan postest kelompok eksperimen 1 dan kelompok eksperimen 2 berdistribusi normal. Sedangkan untuk nilai N-Gain berdistribusi tidak normal artinya setelah uji normalitas $N$-Gain maka langsung uji Mann Whitney. Berikut hasil uji homogenitas.

Tabel 3

Hasil Uji Homogenitas Pretes Kelas Eksperimen dan Kelas Kontrol

\begin{tabular}{|c|c|c|c|c|}
\hline & Levene Statistic & df1 & df2 & Sig \\
\hline Pretes Eksperimen & 0,035 & 1 & 64 & 0,852 \\
\hline Postes Eksperimen & 0,045 & 1 & 64 & 0,833 \\
\hline
\end{tabular}

Berdasarkan output di atas diketahui hasil uji homogenitas pretes eksperimen 1 dan 2 nilai signifikansi adalah sebesar $0,852>0,05$, dan hasil uji homogenitas postes eksperimen 1 dan 2 nilai signifikansi adalah sebesar $0,833>0,05$ maka diterima atau kedua varians homogen. Sehingga dapat disimpulkan bahwa varians data pretes kelas eksperimen 1 dan postes kelas eksperimen 2 adalah homogen.

Selanjutnya akan dilakukan uji kesamaan rata-rata (uji $t$ untuk dua sampel independen) dilakukan untuk mengetahui apakah terdapat perbedaan antara kemampuan awal berpikir kreatif matematis siswa kelas eksperimen 1 dan kemampuan awal berpikir kreatif matematis siswa kelas eksperimen 2. Hipotesisnya sebagai berikut:
$\mathrm{H}_{\mathrm{o}}$ : Tidak terdapat perbedaan rata-rata antara kemampuan awal berpikir kreatif matematis siswa kelas eksperimen 1 dengan rata-rata kelas eksperimen 2

$\mathrm{H}_{1}$ : Terdapat perbedaan rata-rata antara kemampuan awal berpikir kreatif matematis siswa kelas eksperimen 1 dengan rata-rata kelas eksperimen 2

Kriteria pengujian $\mathrm{H}_{\mathrm{o}}$ diterima jika nilai signifikansi dari pengolahan data $>0,05$, sedangkan jika nilai signifikansi $<0,05$ mka $H_{o}$ ditolak. Hasil uji kesamaan rata-rata pretes kemempuan pemecahan masalah matematis siswa kelas eksperimen dan kelas kontrol dapat dilihat pada tabel 4 . 
Tabel 4

Hasil Uji Independen T Tes Pretes

\begin{tabular}{|c|c|c|}
\hline \multirow{3}{*}{$\begin{array}{c}\text { Hasil uji independen } \mathrm{t} \text { tes } \\
\text { pretes }\end{array}$} & $\mathrm{df}$ & Sig (2-tailed) \\
\cline { 2 - 3 } & 54 & .587 \\
\cline { 2 - 3 } & 45.955 & .591 \\
\hline
\end{tabular}

Berdasarkan tabel 4 di atas diperoleh nilai signifikansi untuk uji independen $t$ tes pretes dengan nilai sig (2-tailed) sebesar 0,591>0,05 maka kriteria pengujian $\mathrm{H}_{\mathrm{o}}$ diterima artinya kemampuan berpikir kreatif matematis siswa antara kelas eksperimen 1 dan kelas eksperimen 2 tidak berbeda secara signifikan.

Tabel 5

Hasil Uji Independen T Tes Postes

\begin{tabular}{|c|c|c|}
\hline \multirow{2}{*}{$\begin{array}{c}\text { Hasil uji } \\
\text { independen t tes } \\
\text { postes }\end{array}$} & Df & Sig (2-tailed) \\
\cline { 2 - 3 } & 54 & .974 \\
\cline { 2 - 3 } & 44.684 & .975 \\
\hline
\end{tabular}

Berdasarkan tabel 5 di atas diperoleh nilai signifikansi untuk uji independen $t$ tes postes dengan nilai sig (2-tailed) sebesar 0,975>0,05 maka kriteria pengujian $\mathrm{H}_{\mathrm{o}}$ diterima artinya kemampuan berpikir kreatif matematis siswa antara kelas eksperimen 1 dan kelas eksperimen 2 tidak berbeda secara signifikan.

Uji Mann Whitney digunakan untuk analisis statistik terhadap dua sampel independen bila jenis data yang akan dianalisis bersekala nominal atau oridinal, atau data tidak berdistribusi normal. Dengan hipotesis sebagai berikut:

$\mathrm{H}_{\mathrm{o}}$ : Tidak terdapat perbedaan peningkatan kemampuan berpikir kreatif matematis siswa antara siswa yang mendapatkan pembelajaran model treffingerdengan siswa yang mendapatkan pembelajaran model Creative Problem Solving.

$\mathrm{H}_{1}$ : Terdapat perbedaan peningkatan kemampuan berpikir kreatif matematis siswa antara siswa yang mendapatkan pembelajaran model treffingerdengan siswa yang mendapatkan pembelajaran model Creative Problem Solving.

Kriteria pengujian $\mathrm{H}_{\mathrm{o}}$ diterima jika nilai signifikansi dari pengolahan data $>0,05$, sedangkan jika nilai signifikansi $<\quad 0,05 \quad$ mka $\mathrm{H}_{\mathrm{o}}$ ditolak.

Tabel 6

Hasil uji Mann Withney N-Gain

\begin{tabular}{|c|c|}
\hline Hasil uji mann withney & N-Gain Score \\
\hline Mann-Whitney U & 533.000 \\
\hline Asymp. Sig. (2-tailed) & .882 \\
\hline
\end{tabular}


Berdasarkan tabel 6 di atas diperoleh nilai signifikansi untuk uji mann withney N-Gain dengan nilai sig (2-tailed) sebesar 0,882>0,05 maka kriteria pengujian $\mathrm{H}_{\mathrm{o}}$ diterima dengan demikian dapat dikatakan bahwa Tidak terdapat perbedaan peningkatan kemampuan berpikir kreatif matematis siswa antara siswa yang mendapatkan pembelajaran model Treffinger engan siswa yang mendapatkan pembelajaran model CPS.

\section{PEMBAHASAN}

Hasil penelitian uji mann whitney data N-Gain untuk kelas eksperimen 1 dan kelas eksperimen 2 hasil signifikansinya $0,882>0,05$ artinya pengujian $\mathrm{H}_{\mathrm{o}}$ diterima dan dapat dikatakan bahwa tidak terdapat perbedaan peningkatan kemampuan berpikir kreatif matematis siswa antara siswa yang mendapatkan pembelajaran model Treffinger dengan siswa yang mendapatkan pembelajaran model CPS. Peningkatan kemampuan berpikir kreatif matematis siswa dengan pembelajaran Treffinger sama dengan peningkatan siswa dengan pembelajaran CPS. Tidak adanya perbedaan peningkatan kemampuan berpikir kreatif matematis ini dapat dilihat berdasar hasil analisis data NGain untuk kelas eksperimen 1 sebesar 0,55 dengan kriteria sedang dan kelas eksperimen 2 sebesar 0,56 dengan kriteria sedang. Menurut Maharani (2018:507) "model pembelajaran treffinger memiliki keunggulan yaitu siswa diberi kesempatan memahami berbagai konsep cara memecahkan masalah, mengembangkan kemampuan siswa dalam berpikir dan memaparkan permasalahan, mengumpulkan data, menganalisis data, memciptakan gagasan, dan mencoba sebagai pemecahan permasalahan". Sedangkan menurut Ginting, dkk (2019) "pembelajaran dengan model creative problem solving membiasakan siswa untuk mengembangkan proses berpikir kreatif dalam menyelesaikan masalah dengan langkah-langkah yang terstruktur, sehingga siswa lebih memahami konsep serta mampu mengkomunikasikan pemikirannya". Dengan demikian kedua model pembelajaran tersebut memang samasama dapat meningkatkan pembelajaran siswa di sekolah.

Berdasarkan hasil pengamatan peneliti, penggunaan model pembelajaran Treffinger dan penggunaan model pembelajaran CPS sama-sama menjadikan siswa lebih serius dan tidak merasa malu ataupun takut bertanya kepada guru dan siswa lain. Meskipun tidak seluruh siswa dengan mudah menerima model pembelajaran ini dan merubah cara belajar yang biasa dilaksankan, tetapi pada umumnya pembelajaran Treffinger dan CPS dapat menjadikan siswa lebih aktif dan memahami materi pelajaran yang sedang dipelajari. Menurut Nisa (2011:45) "sintak pada pembelajaran Treffinger adalah basic tools, practice with problems, dan working with real problems". Pada setiap langkahnya, model Treffinger ini dapat melatih siswa untuk berpikir divergen yang dapat melibatkan kemampuan berpikir kreatif matematis siswa. Sedangkan menurut Jeliana (2019:43) "sintak pembelajaran CPS adalah klarifikasi masalah, pengungkapan pendapat, evaluasi dan pemilihan, dan implementasi". Dari setiap langkahnya model CPS dapat melatih siswa untuk memahami setiap masalah matematika dan dapat mengungkapkan pendapat serta dapat memilih strategi yang cocok untuk menyelesaikan setiap permasalahan yang dapat melibatkan kemampuan berpikir kreatif matematis siswa. 
Hasil penelitian memberikan gambaran bahwa pembelajaran Treffinger dan CPS keduanya dapat memberikan proses pembelajaran yang lebih baik untuk meningkatkan kemampuan berpikir kreatif matematis sehingga dapat dijadikan sebagai alternatif pembelajaran di kelas. Treffinger pada practice with problems nya dan CPS pada pengungkapan pendapat dan evaluasi nya. Kegiatan tersebut mampu mengasah kemampuan berpikir dan membuat serta menciptakan gagasan baru dari setiap masalah yang dihadapi. Hal tersebut juga disampaikan oleh oleh simanjuntak, dkk (2019) bahwa Model Pembelajaran Creative Problem Solving (CPS) Tipe Treffinger dapat meningkatkan berpikir kreatif pada pokok bahasan larutan penyangga dalam bidang kimia.

Kelebihan pembelajaran Treffinger dan CPS adalah siswa dapat menerima dan mentransfer ilmu yang telah mereka dapat kepada siswa lainnya dalam proses pembelajaran. Adapun kendala pada penggunaan pembelajaran Treffinger dan CPS adalah pengaturan waktu. Waktu yang digunakan umumnya habis digunakan untuk saling interaksi dan berdiskusi satu sama lain, sehingga waktu yang terpakai tidak efisien karena siswa masih belum terbiasa melakukan kegiatan pembelajaran dengan menggunakan model pembelajaran tersebut. Untuk mengatasi hal tersebut yaitu guru harus bisa mengefektifkan waktu agar waktu yang tersedia cukup untuk proses pembelajaran.

\section{KESIMPULAN}

Berdasarkan hasil analisis, pembahasan, dan penelitian maka kesimpulan penelitian ini adalah tidak terdapat perbedaan peningkatan kemampuan berpikir kreatif matematis siswa antara siswa yang mendapatkan pembelajaran dengan model Treffinger dengan siswa yang mendapatkan pembelajaran dengan model Creative Problem Solving (CPS). Kesimpulan ini dibuktikan berdasarkan data $\mathrm{N}$-gain kelas eksperimen 1 sebesar 0,55 dan $\mathrm{N}$ gain kelas eksperimen 2 sebesar 0,56 serta hasil analisis uji statistik data $\mathrm{N}$ gain dengan signifikasi 0,882 >0,05.

\section{SARAN}

Berdasarkan uraian mengenai kesimpulan, maka disarankan bagi guru matematika untuk mencoba atau menggunakan pembelajaran Treffinger dan CPS dalam proses pembelajaran berlangsung. Bagi sekolah hendaknya untuk memfasilitasi kebutuhankebutuhanyang dibutuhkan dalam melaksanakan pembelajaran di sekolah agar kegiatan pembelajaran berjalan dengan efektif. Bagi para peneliti pendidikan diharapkan dapat melakukan kajian lebih lanjut terhadap pelaksanaan pembelajaran melalui pembelajaran Treffinger dan CPS dengan rumusan masalah yang berbeda.

\section{UCAPAN TERIMA KASIH}

Penulis menyadari bahwa jurnal ini tidak akan pernah terwujud tanpa adanya bantuan dari berbagai pihak.Oleh karena itu,penulis mengucapkan terima kasih kepada:

Dr. Indra Adi Budiman, M.Pd, selaku Dekan Fakultas Keguruan dan Ilmu Pendidikan Universitas Majalengka.

Dr. Yoyo Zakaria Ansori, M.Pd, selaku Wakil Dekan I Fakultas Keguruan dan Ilmu Pendidikan Universitas Majalengka.

Nia Kania, M.Pd, selaku Ketua Program Studi Pendidikan Matematika Fakultas Keguruan dan Ilmu Pendidikan Universitas Majalengka . 
Iik Nurhikmayati, M.Pd, selaku Dosen Wali dan Dosen Pembimbing I di Program Studi Pendidikan Matematika Fakultas Keguruan dan Ilmu Pendidikan Universitas Majalengka.

Erik Santoso, M.Pd, selaku Dosen Pembimbing II di Program Studi Pendidikan Matematika Fakultas Keguruan dan Ilmu Pendidikan Universitas Majalengka.

Segenap dosen staf dan karyawan Fakultas Keguruan dan Ilmu Pendidikan khususnya Program Studi Pendidikan Matematika.

Didi Hardika, Endah Nisa Fauziah, Kartika Apriani, Nurhayati, Sari Agustina, Siti Haifatudzikroh, Nurbelayanti dan Wahyu Eka Santika sahabat seperjuangan yang telah menjadi tempat berbagi suka dan duka selama mengarungi perjuangan menempuh studi di Universitas Majalengka.

\section{DAFTAR PUSTAKA}

[1] Hasanah, E., Darmawan, D., \& Nanang, N. (2019). "Pengaruh Penggunaan Media Pembelajaran Articulate Dalam Metode Problem Based Learning (Pbl) Terhadap Peningkatan Kemampuan Berpikir Kreatif Peserta Didik. Jurnal Teknologi Pendidikan dan Pembelajaran. Vol. 4, No.1, pp. 826838.

[2] Andiyana, A. M., Maya, R., dan Hidayat, W. (2018). "Analisis Kemampuan Berpikir Kreatif Matematis Siswa SMP Pada Materi Bangun Ruang".Jurnal Pembelajaran Matematika Inovatif. Vol. 1, No 3, pp. 239-248.

[3] Sari, Y. I., \& Putra, D. F. (2016)."Pengaruh Model Pembelajaran Treffinger terhadap Kemampuan Berpikir Kritis dan Kreatif Mahasiswa Universitas Kanjuruhan Malang". Jurnal
Pendidikan Geografi. Vol. 20, No. 2, pp.30-38.

[4] Shoimin, A. (2014). 68 Model Pembelajaran Inovatif Dalam Kurikulum 2013.Yogyakarta: ArRuzz Media.

[5] Lestari, K. E., dan Yudhanegara, M. R. (2017). Penelitian Pendidikan Matematika. Bandung: Refika Aditama.

[6] Simanjuntak, F.E., Erviyenni, Noer, A.M/ (2019). Penerapan Model Pembelajaran Creative Problem Solving (CPS) Tipe Treffinger Untuk Meningkatkan Kemampuan Berpikir Pada Pokok Bahasan Larutan Peyangga. Jurnal Pembelajaran Kimia, Vol 4 No 3, Hal 81-87.

[7] Ginting, B. E., Purwanto, E. S., dan Faradillah, A. (2019). "Pengaruh Model Pembelajaran Creative Problem Solving (Cps) Terhadap Kemampuan Berpikir Kreatif Matematis Siswa". Jurnal Gammath, Vol 4, No.1, Hal 1-7.

[8] Maharani, K. R., Indrawati, D. (2018)."Pengaruh Model Pembelajaran Treffinger Terhadap Kemampuan Berpikir Kreatif Pelajaran Matematika Materi Bangun Ruang".Jurnal Pendidikan Guru Sekolah Dasar. Vol 6, No.4, pp. 506-515.

[9] Nisa, T. F. (2011). "Pembelajaran Matematika Dengan Setting Model Treffinger Untuk Mengembangkan Kreativitas Siswa". PEDAGOGIA: Jurnal Pendidikan, Vol. 1, No.1, pp. 35-50.

[10] Jeliana, I. P. (2019). “Keefektifan Model Pembelajaran Creative Problem Solving (CPS) Terhadap Prestasi Belajar Mtematika SMPN 3 Ngabang". Jurnal Derivat. Vol. 6, No. 1, pp. 42-46. 